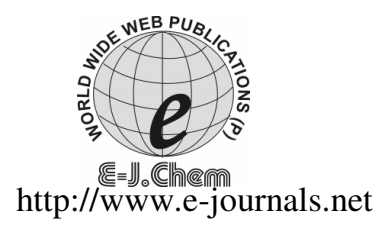

ISSN: 0973-4945; CODEN ECJHAO

E-Journal of Chemistry

2009, 6(S1), S438-S444

\title{
Influence of Formazan Derivatives on Corrosion Inhibition of Mild Steel in Hydrochloric Acid Medium
}

\author{
P.VENKATESAN ${ }^{*}$ B. ANAND and P. MATHESWARAN ${ }^{\S}$ \\ *Mahendra Institute of Technology, Namakkal-637 503, India. \\ Mahendra Engineering College, \\ Namakkal-637 503, India. \\ ${ }^{\S}$ Vidhyaavikaas College of Engineering and Technology, \\ Namakkal-637 503, India. \\ venkatesanps@yahoo.co.in
}

Received 7 April 2009; Accepted 5 June 2009

\begin{abstract}
Formazan of benzaldehyde (FB) and formazan of $p$-dimethyl amino benzaldehyde (FD) were synthesized. These compounds were studied as corrosion inhibitor for mild steel in $1.11 \mathrm{~N}$ hydrochloric acid by weight loss method. The result showed that the corrosion inhibition efficiency of these compounds was found to vary with the temperature and acid concentration. Also, it was found that the corrosion inhibition behaviour of FD is greater than that of FB. The kinetic treatment of the results gave first order kinetics. The relative corrosion inhibition efficiency of these compounds has been explained on the basis of structure dependent - electron donor properties of the inhibitors.
\end{abstract}

Keywords: Mild steel, Corrosion inhibitors, Weight loss method, Formazan derivatives.

\section{Introduction}

Concentrated mineral acids are used extensively in pickling, cleaning, descaling and oil well acidising of metallic materials cause damage of corrosion ${ }^{1,2}$. It has been speculated that organic inhibitors are more effective with iron and that the polar organic compounds containing sulphur and nitrogen are good corrosion inhibitors for the acidic solutions of metals ${ }^{3}$.

High electron density of the sulphur and nitrogen atoms in the heterocyclic organic compounds help the organic molecules to get chemisorbed on to the metal surface ${ }^{4}$. Due to the aggressiveness of hydrochloric acid solution against structural materials, such as carbon steel, the use of corrosion inhibitor is usually required to minimize the corrosion attack ${ }^{5-8}$. Therefore, in this investigation, the corrosion inhibition of mild steel in $1.11 \mathrm{~N} \mathrm{HCl}$ solution in the absence and presence of formazan of benzaldehyde (FB) and formazan of $p$-dimethyl amino benzaldehyde (FD) at various temperatures have been studied by weight loss method. 


\section{Experimental}

According to ASTM method as reported already, ${ }^{9}$ cold rolled mild steel strips were cut into pieces of $5 \mathrm{~cm} \times 1 \mathrm{~cm}$ having the following composition of $\mathrm{Fe}=99.686 \%, \mathrm{Ni}=0.013 \%$, $\mathrm{Mo}=0.015 \%, \mathrm{Cr}=0.043 \%, \mathrm{~S}=0.014 \%, \mathrm{P}=0.009, \mathrm{Si}=0.007 \%, \mathrm{Mn}=0.196 \%$ and $\mathrm{C}$ $=0.017 \%$. They were pickled in pickling solution $\left(5 \% \mathrm{H}_{2} \mathrm{SO}_{4}\right)$ for 3 minutes and washed with distilled water followed by polished with various grades of emery papers and degreased using trichloroethylene. The weight of specimen were noted and then immersed in test solution containing various concentrations of inhibitors at room temperature $303 \mathrm{~K}, 353 \mathrm{~K}$ and $403 \mathrm{~K}$. After the duration of $2 \mathrm{~h}$ in hydrochloric acid, the specimens were removed from test solutions and pickled in pickling (5\% sulphuric acid) solution, dried and finally weighed. The differences in weights were noted and the corrosion rates were calculated.

\section{Solutions}

All the solutions were prepared using NICE brand AR grade chemicals in double distilled water and bubbling purified by nitrogen gas for 30 minutes to carry out de-aeration of the electrolytes. Hydrochloric acid solution was prepared by double distilled water. It was standardized by titrating against sodium carbonate solution and its normality was found to be $1.11 \mathrm{~N}$. The corrosion inhibitor solution of $0.1 \%$ formazan of benzaldehyde was prepared by dissolving $0.1 \mathrm{~g}$ of formazan of benzaldehyde in $100 \mathrm{~mL}$ of test solution. And also, $0.2 \%$, $0.3 \%, 0.4 \%$ and $0.5 \%$ solutions of FB were prepared. Similarly formazan of $p$-dimethyl amino benzaldehyde solutions were prepared.

\section{Results and Discussion}

The corrosion behaviour of mild steel in hydrochloric acid with FD and FB is given in Figure 1, which was studied by weight loss method at different temperatures (303K, 353K and $403 \mathrm{~K}$ ). From the graph, it is observed that the weight loss of mild steel in the acid decreases with increasing concentration of additives, which suggesting that the additives are corrosion inhibitor for mild steel in $1.11 \mathrm{~N} \mathrm{HCl}$. From the data of weight lost method, the corrosion rate $(\mathrm{CR})$ was calculated using the equation:

$\mathrm{CR}=(87.6 \times \mathrm{W}) /(\mathrm{D} \times \mathrm{A} \times \mathrm{T})$

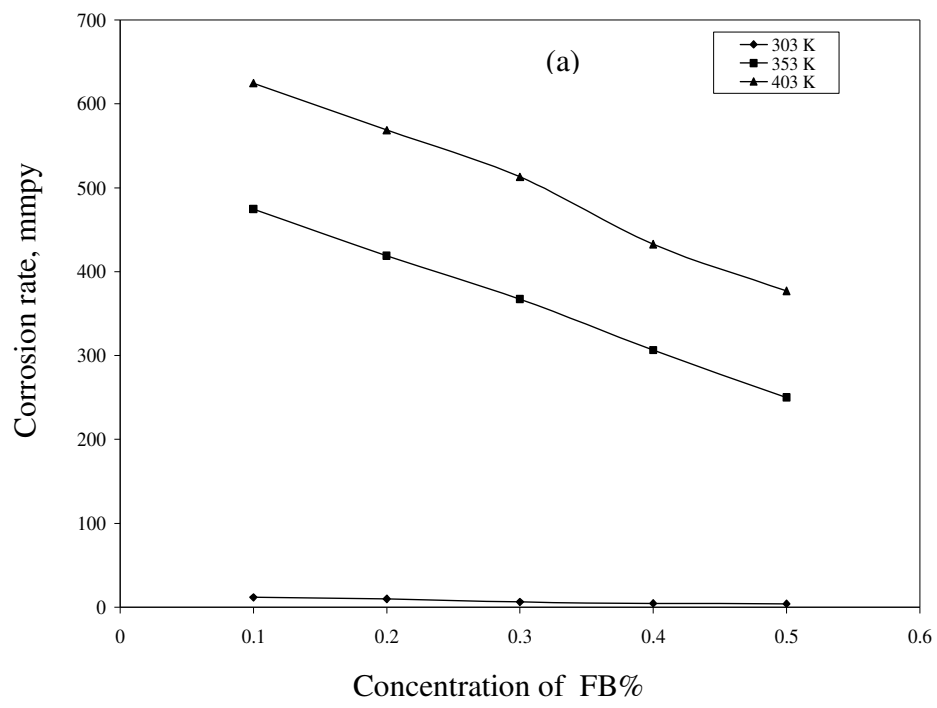



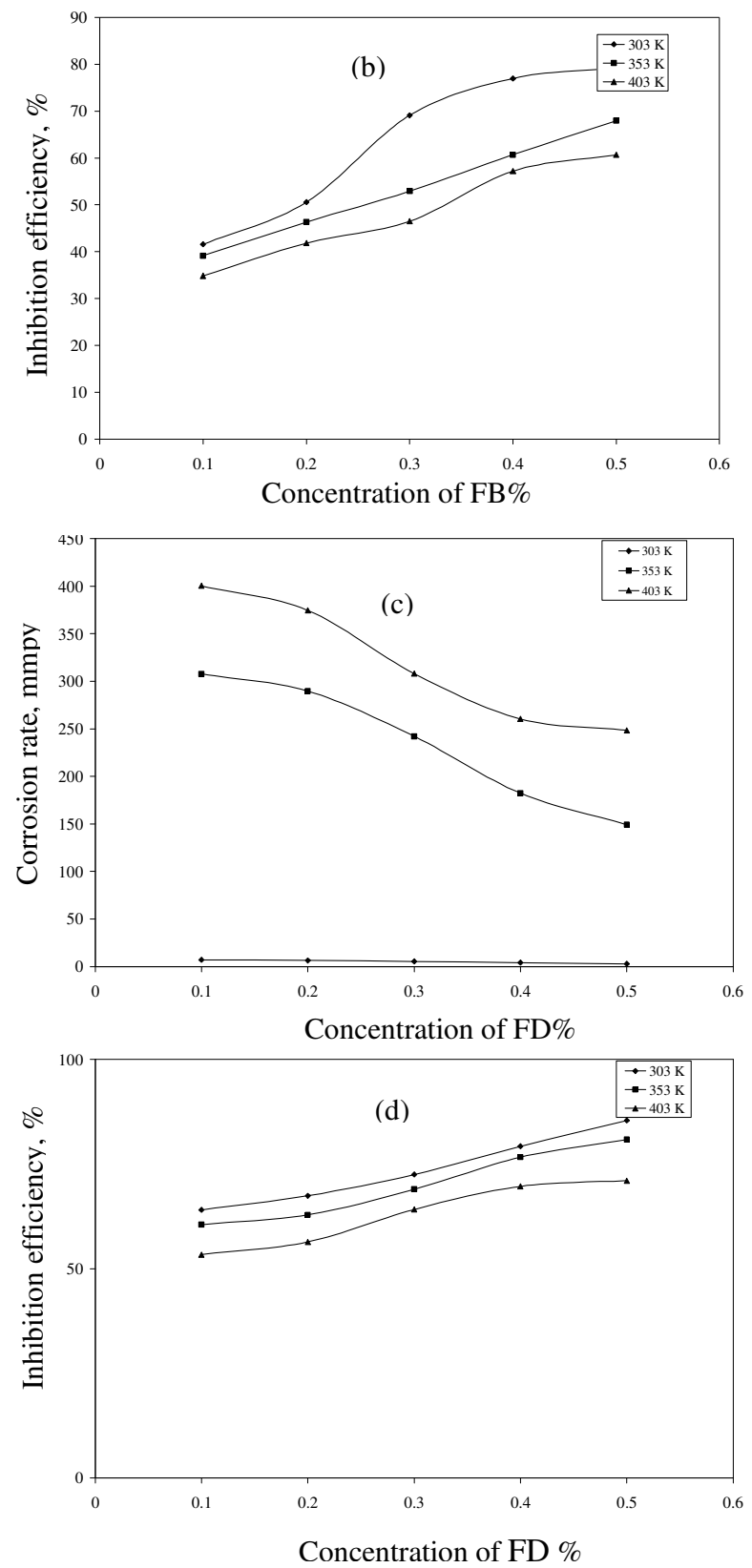

Figure 1 (a) Variation of corrosion rate (CR) with concentration of $\mathrm{FB}$ (in \%) in $\mathrm{HCl}$ solution at different temperature, (b). Variation of inhibition efficiency (IE) with concentration of $\mathrm{FB}$ (in \%) in $\mathrm{HCl}$ solution at different temperature, (c). Variation of corrosion rate (CR) with concentration of $\mathrm{FD}$ (in \%) in $\mathrm{HCl}$ solution at different temperature, (d). Variation of inhibition efficiency (IE) with concentration of FD (in \%) in $\mathrm{HCl}$ solution at different temperature. 
Where W, D, A and T are weight lose (in $\mathrm{mg}$ ), density of mild steel (7.86 g/cc), area of the specimen in cm square and exposure time in hours respectively.

Similarly, Inhibition efficiency was calculated using the equation,

$$
\text { IE } \%=\left[\left(\mathrm{W}_{\mathrm{o}}-\mathrm{W}_{\mathrm{i}}\right) / \mathrm{W}_{\mathrm{o}}\right] \times 100
$$

Where $\mathrm{W}_{\mathrm{o}}$ and $\mathrm{W}_{\mathrm{i}}$ are the values of the weight loss (in $\mathrm{g}$ ) of mild steel in the absence and presence of inhibitor respectively. The values of corrosion rate and inhibition efficiency in absence and presence of difference concentration of inhibitor used in $1.11 \mathrm{~N} \mathrm{HCl}$ solution at 303,353 and $403 \mathrm{~K}$ for 2 hours were given in Table 1.

Table 1. Corrosion inhibition behaviour of mild steel in $1.11 \mathrm{~N} \mathrm{HCl}$ solution in absence and presence of FB and FD by weight loss measurement.

\begin{tabular}{cccccccc}
\hline \multirow{2}{*}{$\begin{array}{c}\text { Corrosion } \\
\text { Inhibitors }\end{array}$} & $\begin{array}{c}\text { Conc. of } \\
\text { inhibitor, } \%\end{array}$ & \multicolumn{3}{c}{ Corrosion Rate $(\mathrm{mm} / \mathrm{y})$} & \multicolumn{3}{c}{ Inhibition Efficiency, \% } \\
\cline { 3 - 9 } & Blank & 19.84 & 780.04 & 958.81 & - & - & - \\
& 0.1 & 11.59 & 474.67 & 624.68 & 41.57 & 39.15 & 34.85 \\
\multirow{3}{*}{ FB } & 0.2 & 9.81 & 418.94 & 568.73 & 50.56 & 46.29 & 41.84 \\
& 0.3 & 6.13 & 367.34 & 513.01 & 69.10 & 52.91 & 46.49 \\
& 0.4 & 4.57 & 306.49 & 432.76 & 76.97 & 60.71 & 57.18 \\
& 0.5 & 4.12 & 249.87 & 377.04 & 79.21 & 67.97 & 60.67 \\
& Blank & 19.84 & 780.04 & 858.50 & - & - & - \\
& 0.1 & 7.13 & 307.83 & 400.44 & 64.04 & 60.54 & 53.36 \\
FD & 0.2 & 6.46 & 289.66 & 374.47 & 67.42 & 62.87 & 56.38 \\
& 0.3 & 5.46 & 242.18 & 308.05 & 72.47 & 68.95 & 64.12 \\
& 0.4 & 4.12 & 182.33 & 260.46 & 79.21 & 76.63 & 69.66 \\
& 0.5 & 2.90 & 149.23 & 248.53 & 85.39 & 80.87 & 71.05 \\
\hline
\end{tabular}

From Table 1, it is clear that the corrosion rate is decreased with increasing concentration of inhibitor and inhibition efficiency increased with increasing the concentration of the inhibitor. In addition, the maximum corrosion inhibition efficiency of FD and FB is $85.39 \%, 79.21 \%$ respectively in $1.11 \mathrm{~N} \mathrm{HCl}$ at $0.5 \%$ solution of inhibitor in $303 \mathrm{~K}$. And also, it is concluded that FD was best inhibitor in mild steel corrosion in $\mathrm{HCl}$ when compared with that of FB.

\section{Kinetic Studies}

In addition, the experiment was conducted at different immersion time to study the rate of reaction. The plot of log (weight loss) versus immersion time as shown in Figure 2, give a straight line indicating that it follows first order reaction. The values of the rate constant was calculated using the first order rate $\operatorname{law}^{10}, \mathrm{k}=(2.303 / \mathrm{t}) \log \left(\left[\mathrm{A}_{\mathrm{o}}\right] /[\mathrm{A}]\right)$. Here $\left[\mathrm{A}_{\mathrm{o}}\right]$ is the initial mass of the metal and $[\mathrm{A}]$ is the mass corresponding to time ' $\mathrm{t}$ '.

The half-life $\left(\mathrm{t}_{1 / 2}\right)$ were calculated using the relationship ${ }^{11}, \mathrm{t}_{1 / 2}=0.693 / \mathrm{k}$. The values of rate constant and half-life $\left(\mathrm{t}_{1 / 2}\right)$ obtained from the above relations are summarized in Table 2. Half life values are found to be constant at different immersion time. The constant value of the rate constant further confirmed that the corrosion of mild steel in $\mathrm{HCl}$ solution in presence of FB and FD follows first order reaction. 


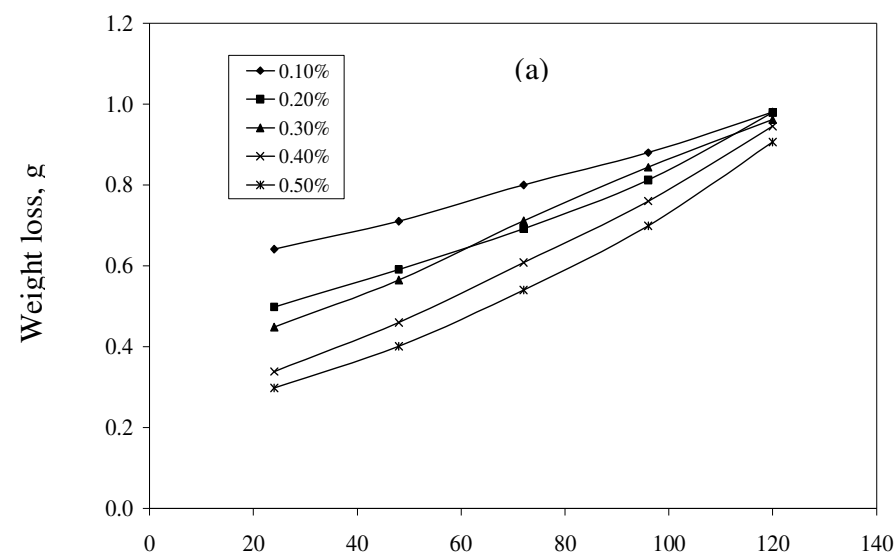

Time, $\mathrm{h}$
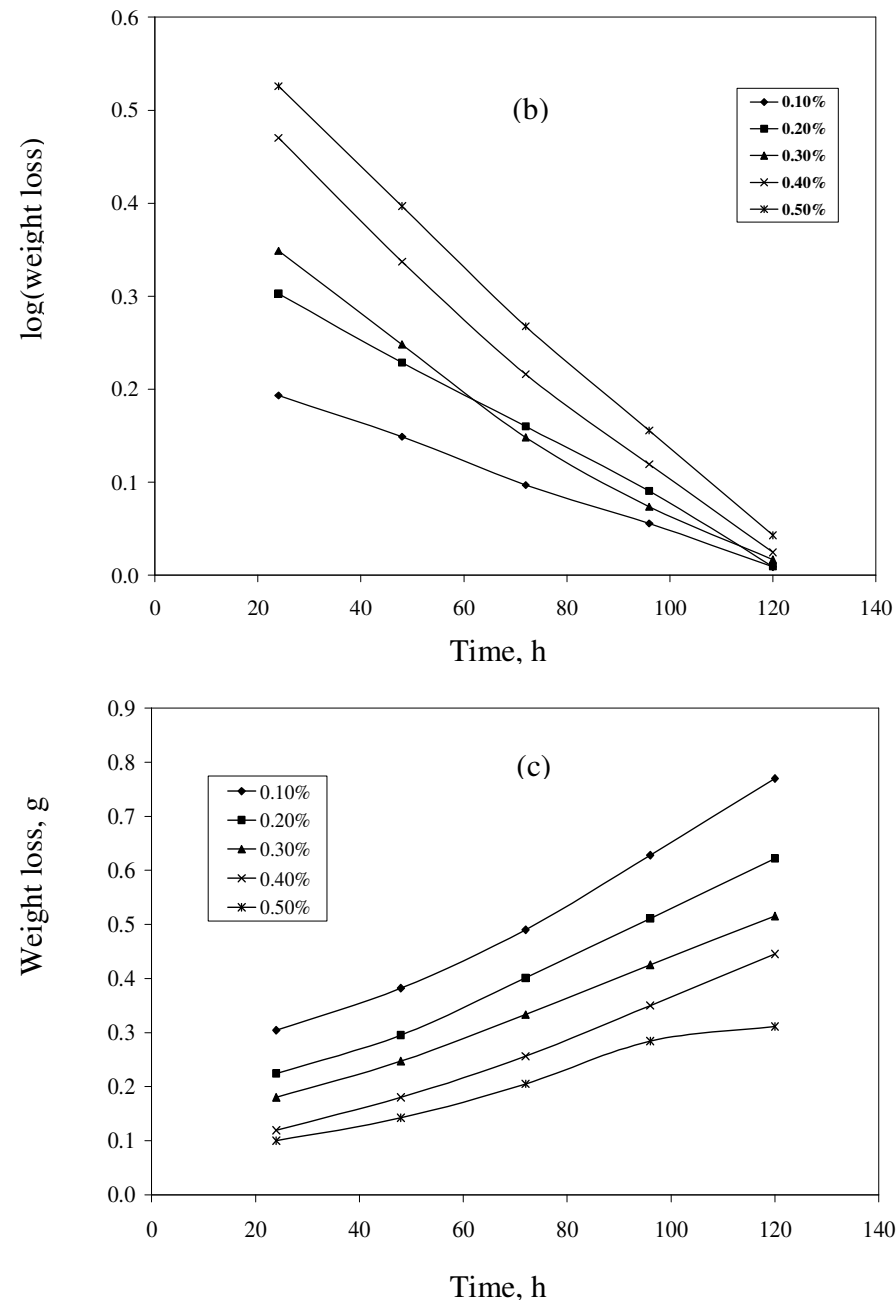


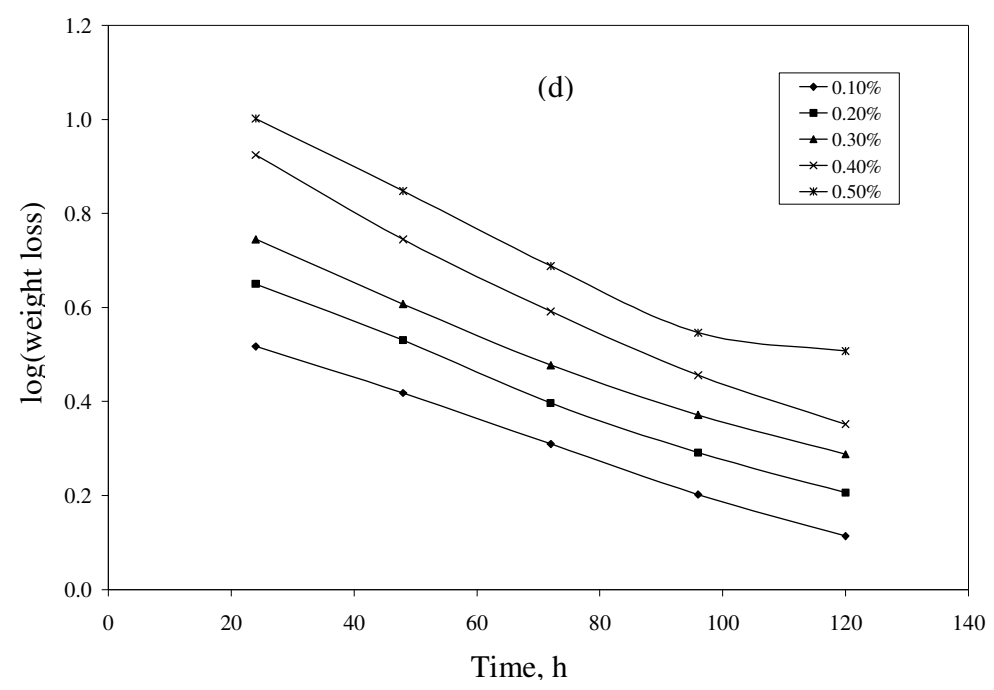

Figure 2 (a). Half life plot for weight loss with immersion time in $\mathrm{HCl}$ solution in the presence of FB at $303 \mathrm{~K}$, (b). Half life plot for log (weight loss) with immersion time in $\mathrm{HCl}$ solution in the presence of $\mathrm{FB}$ at $303 \mathrm{~K}$, (c). Half life plot for weight loss with immersion time in $\mathrm{HCl}$ solution in the presence of $\mathrm{FD}$ at $303 \mathrm{~K}$, (d). Half life plot for log (weight loss) with immersion time in $\mathrm{HCl}$ solution in the presence of $\mathrm{FB}$ at $303 \mathrm{~K}$.

Table 2. Rate constant (k) and half-life values for the corrosion of mild steel at different immersion times in $1.11 \mathrm{~N} \mathrm{HCl}$ solution in absence and presence of inhibitors of different concentration at $303 \mathrm{~K}$.

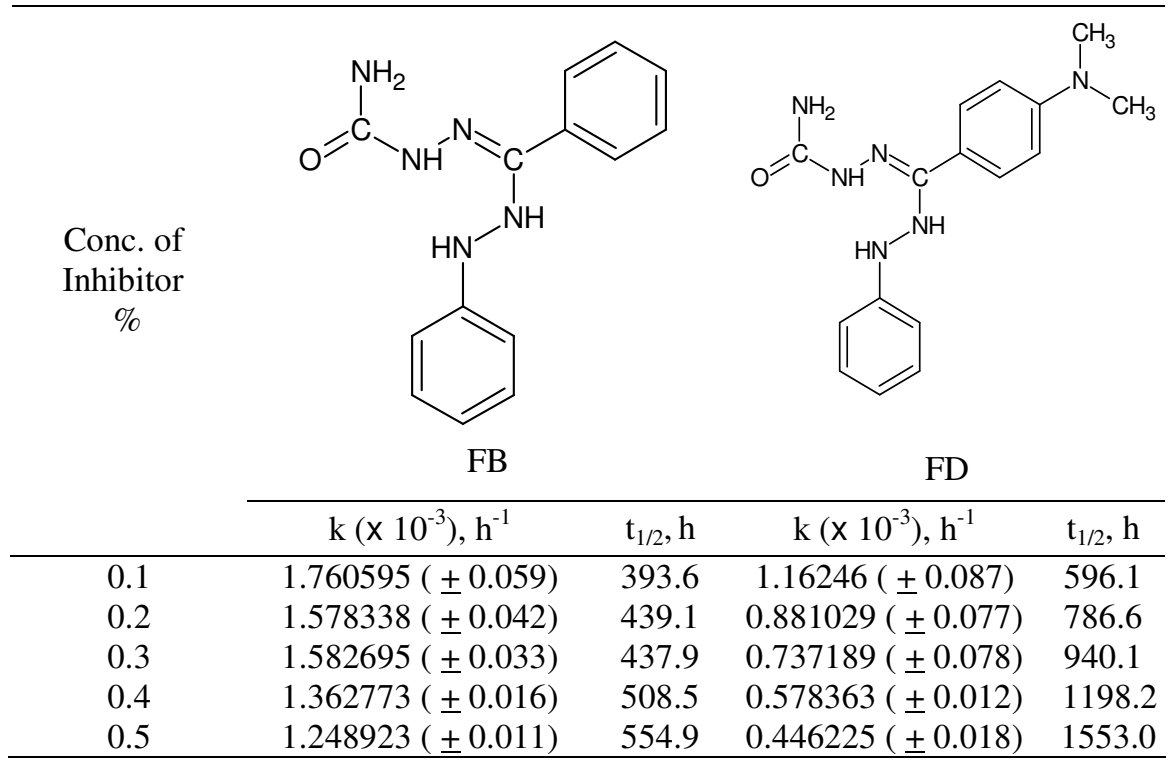




\section{Comparison of corrosion inhibitory behaviour of $F B$ and $F D$}

Since hydrazinecarboxamide and phenylhydrazine groups are basic in nature due to availability of electrons on $\mathrm{N}$ atom, it act as adsorption center. Hence, both FB and FD shows goods inhibitory character. However, $N, N$-dimethyl group in phenylmethylidene ring induces more basic nature to FD. Hence the $\mathrm{N}$ atom in FD therefore undoubtly has high electron density for adsorption on to the mild steel surface than FB. So, inhibition behaviour of FD increases tremendously when compared to that of FB.

\section{Conclusions}

The FB and FD showed good performance as corrosion inhibitor in $\mathrm{HCl}$ solution medium due to the presence of heteroatom and unsaturated bond that cause effective adsorption process leading to the formation of an insoluble protective surface film which suppresses the metal dissolution reaction. First order types of reaction were observed in the kinetic studies. The inhibition efficiency increased with increase in concentration of inhibitors for $0.1 \%$ to $0.5 \%$ and decreased with rise in temperature from $303 \mathrm{~K}$ to $404 \mathrm{~K}$. The maximum inhibition efficiency of FB and FD were $79.21 \%$ and $85.39 \%$ respectively in $1.11 \mathrm{~N} \mathrm{HCl}$ at $303 \mathrm{~K}$ $(0.5 \%)$ for 2 hours of immersion time. From the studies, it was concluded that FD was efficient inhibitor in mild steel corrosion when compared with FB in hydrochloric acid medium.

\section{References}

1. Desai M N and Desai M B, Corros Sci., 1984, 24, 649.

2. Sazou D, Georgolios C and Pagitsas M, Electrochim Acta, 1993, 38, 2321.

3. Noor E A. Corros Sci., 2005, 47, 33.

4. Ebenso E E, Ekpe U J, Ita B I, Offiong O E and Ibok U J, Mater Chem Phy., 1999, 60, 79.

5. Ayers R C and Hackerman N, J Electrochem Soc., 1963, 110, 507.

6. Schmitt G, Inhibitors for chemical cleaning treatment in corrosion inhibitors; Working Party Report - II; Inst. of Materials: London, 1994, 64.

7. Trabanelli G, Inhibition for chemical, cleaning treatment in corrosion inhibitors; Working Party Report - II; Inst. of Materials: London, 1994, 92.

8. Trabanelli G, Zucchi F and Brunoro G, Werkst Korros., 1988, 39, 512.

9. Abiola O K, Oforka N C and Ebenso E E, Bull Electrochem., 2004, 20, 409.

10. Orubite-Okorosaye K and Oforka N C, J Appl Sci Environ., 2004, 8, 57.

11. Atkins P W, A textbook of physical chemistry; University press: London, 1980, 936. 


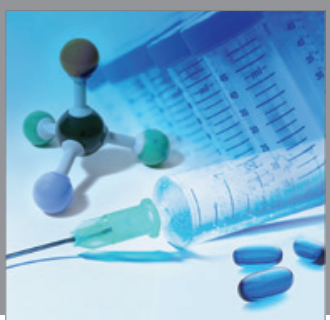

International Journal of

Medicinal Chemistry

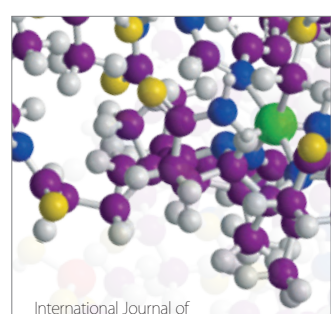

Carbohydrate Chemistry

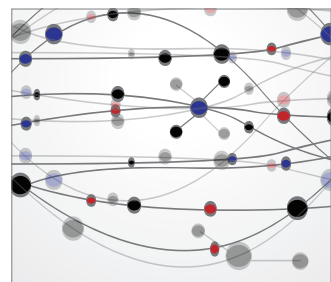

The Scientific World Journal
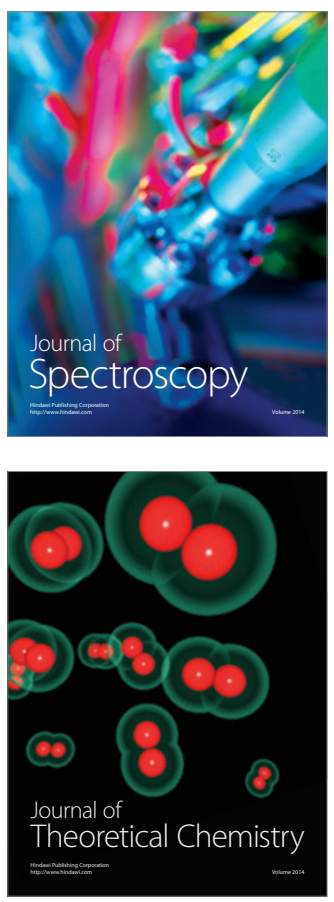
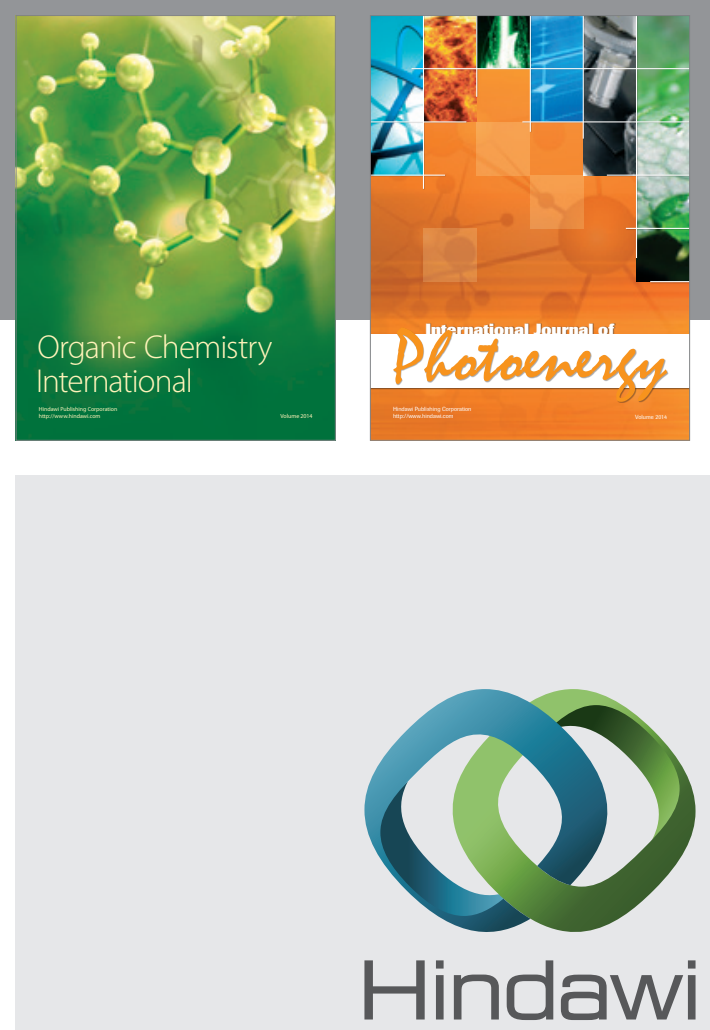

Submit your manuscripts at

http://www.hindawi.com
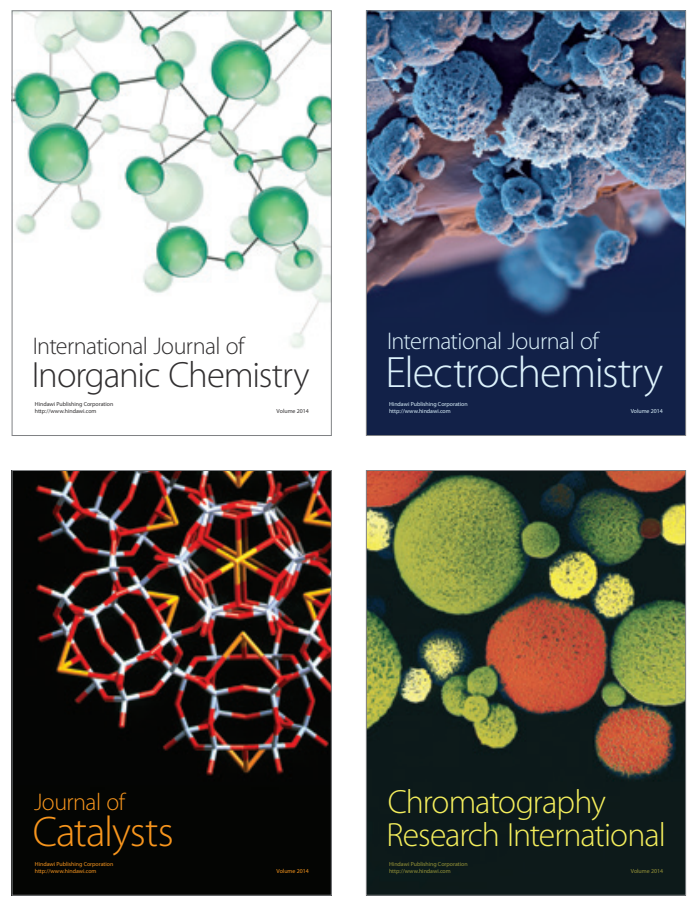
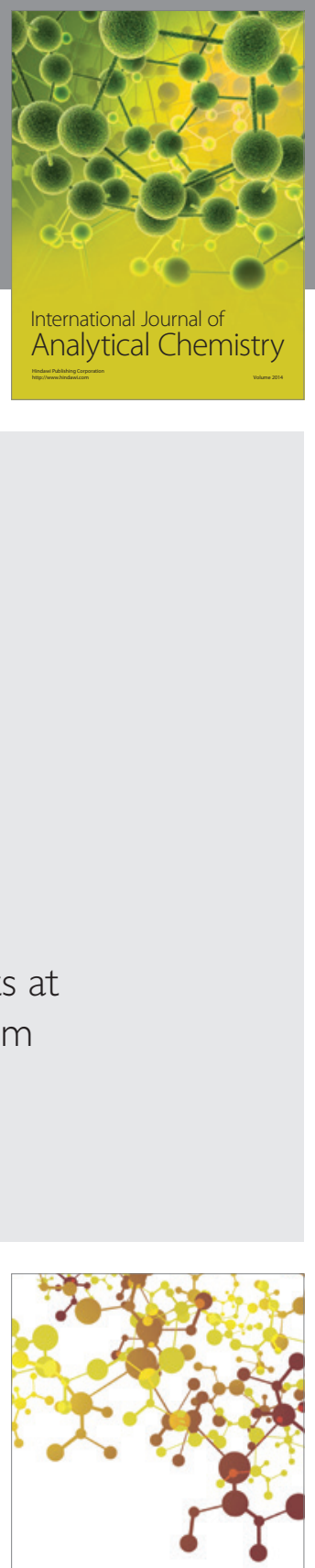

Journal of

Applied Chemistry
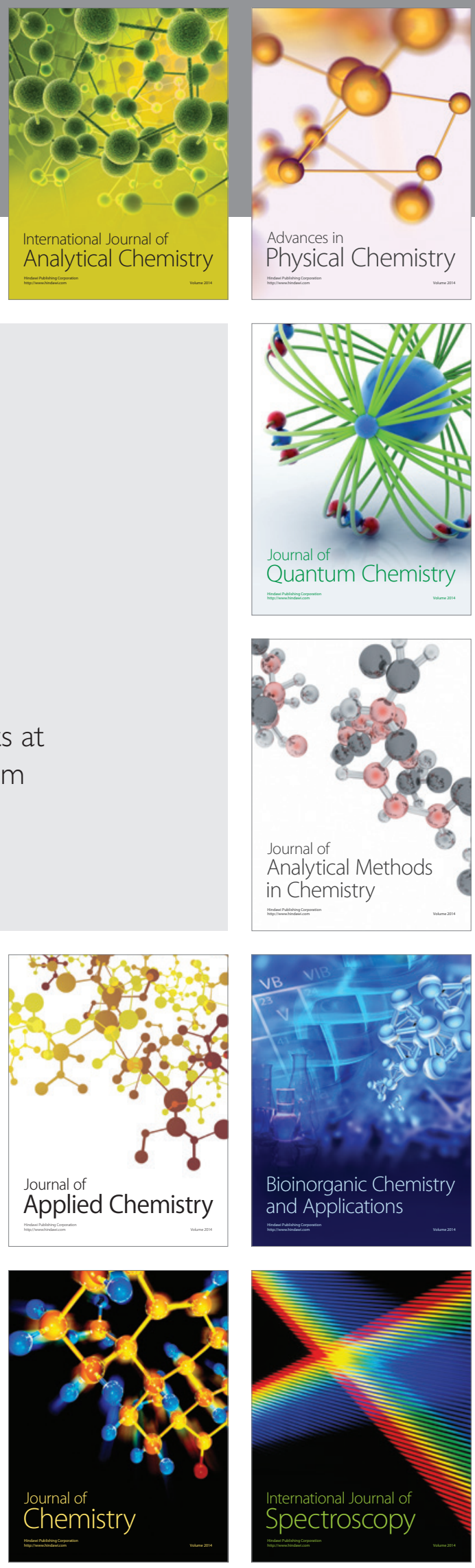